\title{
Comparative study: the effect of annealing conditions on the properties of P3HT:PCBM blends
}

David E. Motaung, Gerald F. Malgas, Steven S. Nkosi, Gugu H. Mhlongo, Bonex W. Mwakikunga, Thomas Malwela, Christopher J. Arendse, Theophillus F. G. Muller and Franscious R. Cummings

\begin{abstract}
This paper presents a detailed study on the role of various annealing treatments on organic poly(3-hexylthiophene) and [6]-phenyl-C61-butyric acid methyl ester blends under different experimental conditions. A combination of analytical tools is used to study the alteration of the phase separation, structure and photovoltaic properties of the $\mathrm{P}_{3} \mathrm{HT}: \mathrm{PCBM}$ blend during the annealing process. Results showed that the thermal annealing yields PCBM "needle-like" crystals and that prolonged heat treatment leads to extensive phase separation, as demonstrated by the growth in the size and quantity of PCBM crystals. The substrate annealing method demonstrated an optimal morphology by eradicating and suppressing the formation of fullerene clusters across the film, resulting in longer $\mathrm{P}_{3} \mathrm{HT}$ fibrils with smaller diameter. Improved optical constants, PL quenching and a decrease in the $\mathrm{P}_{3} \mathrm{HT}$ optical bad-gap were demonstrated for the substrate annealed films due to the limited diffusion of the PCBM molecules. An effective strategy for determining an optimized morphology through substrate annealing treatment is therefore revealed for improved device efficiency.
\end{abstract}

\section{Introduction}

Organic photovoltaic (OPV) solar cells have attracted significant attention due to their great potential for large-area, light-weight, flexible, and low-cost devices [1-4]. Recently, OPV research has been dominated by the poly(3-hexylthiophene):[6]-phenyl C61-butyric acid methyl ester ( $\mathrm{P}_{3} \mathrm{HT}$ : PCBM) blend reaching power conversion efficiencies (PCEs) of $5-7 \%$ [5, 6]. Most recently a record PCE of about 8.13 and $8.5 \%$ has been reported [7, 8]. Despite recent achievements, improvement in PCEs, stability and lifetime of the devices are necessary before organic solar cells become commercially viable [9-11]. The PCE of the solar cells based on the $\mathrm{P} 3 \mathrm{HT} /$ fullerene system depends strongly on the processing conditions [12] and can be improved by increasing the crystalline content of the $\mathrm{P}_{3} \mathrm{HT}$. Different approaches have been suggested for the optimization of the morphology, such as thermal annealing [5, 6, 13-15], solvent annealing [16], electric field treatment [17], the use of various solvent additives, e.g., alkanedithiols [18], 1-chloronaphthalene [19], 1,8-diiodooctane [20], and nitrobenzene [21], or the use of different solvents $[22,23]$ to lead to a molecular 
rearrangement of the spin-coated film. Thermal annealing has been shown to be a critical step in the fabrication of $\mathrm{P} 3 \mathrm{HT} / \mathrm{PCBM}$ solar cells [24]. In most cases to find the optimal annealing time and temperature requires many devices with many annealing conditions. Differential scanning calorimetric (DSC) has been employed to study the glass transition temperature, crystallinity and the melting point of the P3HT; nevertheless, this does not provide a specific annealing temperature for best device performance [25].

Although thermal annealing of the P3HT:PCBM blend has been reported on extensively, little or no comparative studies has been reported on the effect of thermal (in air and under argon (Ar) atmospheres) and substrate annealing on the structure, morphology, optical, and photovoltaic properties of the $\mathrm{P}_{3} \mathrm{HT}: \mathrm{PCBM}$ blend. Therefore, in this contribution we report on the role of various annealing treatments on the organic P3HT:PCBM blend by employing thermal (conventional), and substrate annealing strategies at various conditions, temperatures, and times. We demonstrate in detail that the thermal annealing results in PCBM "needle-like" crystals and that prolonged heat treatment leads to extensive phase separation, as demonstrated by the growth in the size and quantity of PCBM crystals-this result in lower power conversion efficiencies. We also emphasize that the substrate annealing method leads to optimal morphology which results in the formation of "fibrillar-like" structures by eradicating and suppressing the formation of the fullerene clusters across the film, which results in improved efficiencies.

\section{Experiment details}

\section{Sample preparation}

The blended films were prepared according to the following procedure. Regioregular $\mathrm{P}_{3} \mathrm{HT}$ (molecular weight $\mathrm{Mn}_{\mathrm{n}} * 64, \mathrm{ooo} \mathrm{g} \mathrm{mol}^{-1}$, regioregularity [98.5\% and PCBM (99.5\% purity) poly(3,4-ethylenedioxythiophene):poly(styrenesulfonate) (PEDOT:PSS) and chlorobenzene (anhydrous, C99 \%) were purchased from Sigma-Aldrich and used as received.

The active layer containing $\mathrm{P}_{3} \mathrm{HT}$ ( ${ }^{*} 5 \mathrm{mg}$ or a weight percentage of $50 \%$ ) and $\mathrm{PCBM}$ with a concentration of ${ }^{*} 5 \mathrm{mg}$ was dissolved in $1 \mathrm{~mL}$ of chlorobenzene (CB) solution to obtain a ratio of $1: 1$ by weight. The $\mathrm{CB}$ solution was used since it has a relatively high boiling point $\left(111.0^{\circ} \mathrm{C}\right)$, and because spin-coated films must have some remaining solvent for controlling the growth rate of the films. The solution was stirred overnight on a hotplate at $50{ }^{\circ} \mathrm{C}$ to attain a complete dissolution. The thin films were obtained by spincoating the constituents on top of ultra-sonically cleaned indium tin oxide and silicon substrates. Film thicknesses were measured using spectroscopic ellipsometry (Table 1). The annealing process was carried out according to the following schemes: (i) films were annealed at different conditions (in air and Ar atmospheres) at $80-160{ }^{\circ} \mathrm{C}$ for $15 \mathrm{~min}$, (ii) the temperature was fixed at $140{ }^{\circ} \mathrm{C}$ and measurements were taken over time $\left(5^{-} 30\right.$ min) to find an optimal annealing time, and (iii) the substrates were annealed at $80-160{ }^{\circ} \mathrm{C}$ on a hot plate in air for $15 \mathrm{~min}$, prior to spin-coating the photoactive layer to control the evaporation rate of the solvent. In this experiment the Ar gas was allowed to flow at 200 sccm. 
Solar cells were fabricated by means of hot-pressing. The counter electrode of the cell consisted of an aluminium coated indium tin-oxide (ITO)/glass substrate. The ITO/ PEDOT:PSS/P3HT:PCBM acted as the working electrode and was placed at an appropriate displacement on top of the glass/ITO/Al counter electrode. The two electrodes were sealed using $25 \mathrm{~lm}$-thick Surlyn ${ }^{\circledR}$ and applying a pressure of $1 \mathrm{MPa}$ for $2 \mathrm{~min}$ at $100{ }^{\circ} \mathrm{C}$ using a hydrostatic pressurizer with hot plates.

\section{Characterization methods}

X-ray diffraction (XRD) patterns of the annealed films were recorded using a Panalytical X'pert PRO PW 3040/60 X-ray diffractometer with a $\mathrm{Cu} \mathrm{K}_{a}(k=0.154 \mathrm{~nm})$ monochromated radiation source, operating at $45.0 \mathrm{kV}$ and $40.0 \mathrm{~mA}$. Data were recorded in the $2 h$ range of $1-25^{\circ}$ with a step size of $0.02^{\circ}$. All measurements were carried out at room temperature. The morphology of the annealed films was measured using AFM (Digital Instruments, Veeco Nanoscope IV Multi-Mode) in tapping mode, and a high resolution scanning electron microscopy (HR-SEM, Auriga ZEISS), which was operated at $2 \mathrm{kV}$. For polarised optical microscopy (POM) analysis, spin-coated thin films were placed between two covering glasses and placed on a Linkam hot-stage (Linkam Scientific Instruments Ltd, UK), mounted on a POM instrument.

Table 1 Fitting errors and the thickness of different films annealed at various conditions

\begin{tabular}{|c|c|c|c|c|c|c|}
\hline \multirow[t]{2}{*}{ Temperatures $\left({ }^{\circ} \mathrm{C}\right)$} & \multicolumn{2}{|c|}{ Annealed in air } & \multicolumn{2}{|c|}{ Annealed in Ar } & \multicolumn{2}{|c|}{ Substrate annealed } \\
\hline & MSE & Thickness (nm) & MSE & Thickness (nm) & MSE & Thickness (nm) \\
\hline As-prepared (RT) & 18.73 & 95.65 & 18.73 & 95.65 & 18.73 & 95.65 \\
\hline 80 & 22.95 & 160.72 & 20.02 & 126.73 & 22.42 & 108.96 \\
\hline 100 & 27.21 & 235.14 & 23.64 & 165.96 & 28.60 & 112.49 \\
\hline 120 & 20.18 & 283.74 & 28.15 & 238.68 & 25.99 & 119.52 \\
\hline 140 & 17.58 & 296.79 & 26.52 & 246.56 & 25.85 & 121.78 \\
\hline 150 & 26.12 & 317.35 & 19.85 & 267.91 & 21.33 & 133.74 \\
\hline
\end{tabular}

A UV/Visible spectrophotometer (Perkin-Elmer Lambda 750 UV-Vis) was used to characterize the absorption properties of the P3HT:PCBM layer in the 200-900 nm wavelength range at room temperature. The photoluminescence (PL) measurements were carried out to characterize the P3HT:PCBM blended films using a Jobin-Yvon NanoLog spectrometer. The emission was detected with a Jobin-Yvon PMT detector. Ellipsometry measurements were performed using a Woollam J.A., M-2000 variable angle spectroscopic ellipsometer with rotating analyzer, VASE. The ellipsometric angles $\Psi$ and $\Delta$ were obtained for variable incidence angles by measuring the complex Fresnel reflection coefficients $r_{\mathrm{p}}$ and $r_{\mathrm{S}}$

$\frac{r_{\mathrm{p}}}{r_{\mathrm{s}}}=\tan (\psi) \cdot e^{i \Delta}$ 
Measurements were obtained in the range of $250-1000 \mathrm{~nm}$ at room temperature

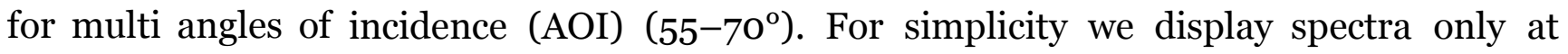
$70^{\circ}$ AOI since they behave similarly at different AOI. The films were regarded as a homogeneous material with film thickness modelled using a Cauchy model [27]. The experimental data were fitted to obtain the optical functions of the blends using a Lorentz model. Model parameters were obtained by minimizing the error function which is defined by the following equation [28]:

$$
\operatorname{MSE}=\frac{\sum\left[\frac{\left|\tan \left(\psi_{\exp }\right)-\tan \left(\psi_{\text {cal }}\right)\right|}{\sigma_{\text {tan }}(\psi)}\right]^{2}+\left[\frac{\left|\cos \left(\Delta_{\text {exp }}\right)-\cos \left(\Delta_{\text {cal }}\right)\right|}{\sigma_{\cos }(\Delta)}\right]^{2}}{N-M-1}
$$

where MSE is the mean square error, $\Psi_{\text {exp }}, \Delta_{\text {exp }}$ are the measured values and $\Psi_{\text {cal }}$, $\Delta_{\text {cal }}$ are the calculated values, $N$ is the number of wavelengths at which measurements were performed, and $M$ is the number of parameters used in fitting. The current-voltage (I$V)$ characteristics were measured using a Keithley 4200 Semiconductor Characterization System. The devices were irradiated at $100 \mathrm{~mW} \mathrm{~cm}^{-2}$ using a xenon short arc lamp-based Sciencetech SF150 solar simulator with a power of $150 \mathrm{~W}$. It should be noted that for consistency, all the as-prepared results were kept the same in order to compare the results measured at different conditions.

\section{Results and discussion X-ray diffraction}

The structural analysis of the $\mathrm{P}_{3} \mathrm{HT}$ :PCBM films annealed at different conditions (air, Ar and substrate annealing) was obtained by XRD. Figure 1 illustrates the effect of different annealing conditions on the structure of the $\mathrm{P}_{3} \mathrm{HT}: \mathrm{PCBM}$ thin films. The as-prepared film shows a weak diffraction peak at $5.35^{\circ}$, which is associated with the (100) reflection of the $\mathrm{P}_{3} \mathrm{HT}$. This peak corresponds to the a-axis orientation, with the main polymer chain parallel and the side chains perpendicular to the substrate [29]. It is observed that the films annealed at different temperatures in air and $\mathrm{Ar}$ atmospheres result in improved diffraction peaks, indicating an improvement of the degree of crystallization of the $\mathrm{P}_{3} \mathrm{HT}$ structure [30]. However, annealing at higher temperature $\left(150{ }^{\circ} \mathrm{C}\right)$ demonstrated a decrease in the diffraction peaks of both films annealed in air and $\mathrm{Ar}$ atmospheres due to a slight disordering in the $\mathrm{P}_{3} \mathrm{HT}$ structure. It is interesting to point out that the substrate annealed films reveal sharper diffraction peaks compared to the thermally annealed films, indicating enhancement in the crystallite sizes (Fig. 2), estimated with the Scherrer formula [31]:

$$
L=\frac{0.9 \lambda}{B_{2 \theta} \cos (\theta)}
$$

where $\lambda$ is the wavelength of the X-rays, $B_{2} \mathrm{~h}$ is the full width at half maximum intensity (FWHM) and $\theta$ is the diffraction angle. 


\section{Atomic force microscopy}

To determine the optimal morphology and the phase separation between the $\mathrm{P}_{3} \mathrm{HT}$ and PCBM, the films were annealed at different temperatures and times. Measurements were taken over time to find an optimal annealing time. The topography of the films was determined by the AFM technique. AFM images of the polymer blended films revealed the surface morphology variation of the $\mathrm{P}_{3} \mathrm{HT}: \mathrm{PCBM}$ as a function of annealing temperature. It is evident that the height image (Fig. 3a) of the as-prepared film reveals small PCBM domains which are distributed evenly across the film. It can be seen that when the film is annealed at $80{ }^{\circ} \mathrm{C}$ small "needle-like" crystals and PCBM clusters are observed, Fig. 3b. However, when the $\mathrm{P}_{3} \mathrm{HT}$ :PCBM film is annealed at $140{ }^{\circ} \mathrm{C}$ (for $15 \mathrm{~min}$ ), the size of the "needle-like" crystals increases as shown in Fig. 3c. The results also revealed that the "needle-like" crystals grow at an early (for $5 \mathrm{~min}$ ) annealing stage (results not shown). This indicates that the crystallization process starts rapidly during the first stages of the thermal annealing process. As high-density $\mathrm{P}_{3} \mathrm{HT}$ crystals start to form, pathways between the polymer's crystallites are created, which facilitate the diffusion of the PCBM molecules. It is evident from Fig. 3d that prolonged (30 min) heat treatment results in extensive phase separation, as demonstrated by the large growth and quantity of the PCBM crystals. At longer annealing times the $\mathrm{P}_{3} \mathrm{HT}$ chains become soft and flexible, and the surface of the blended film becomes flatter than that at the shorter annealing time.
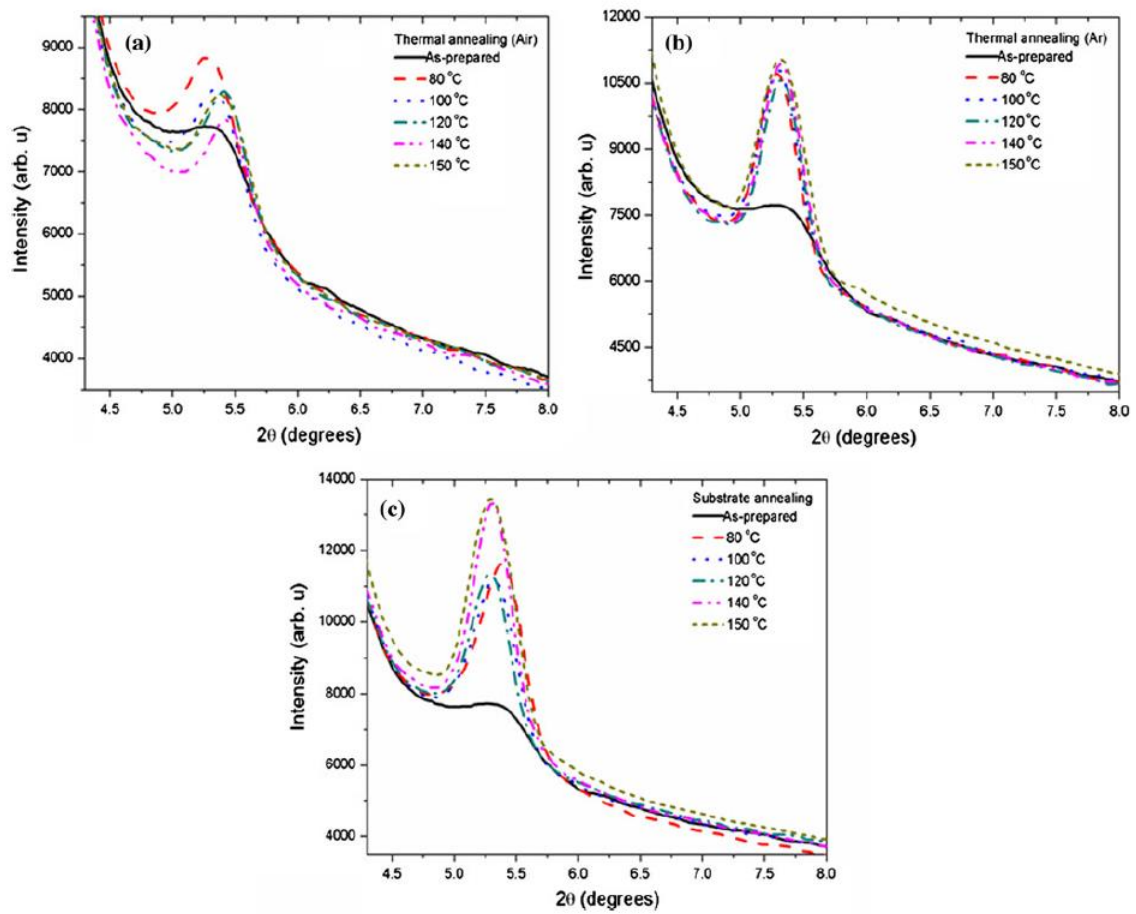

Fig. 1 X-ray diffraction patterns of the P3HT:PCBM films annealed in a air, $\mathbf{b}$ Ar atmosphere and $\mathbf{c}$ substrate annealed 


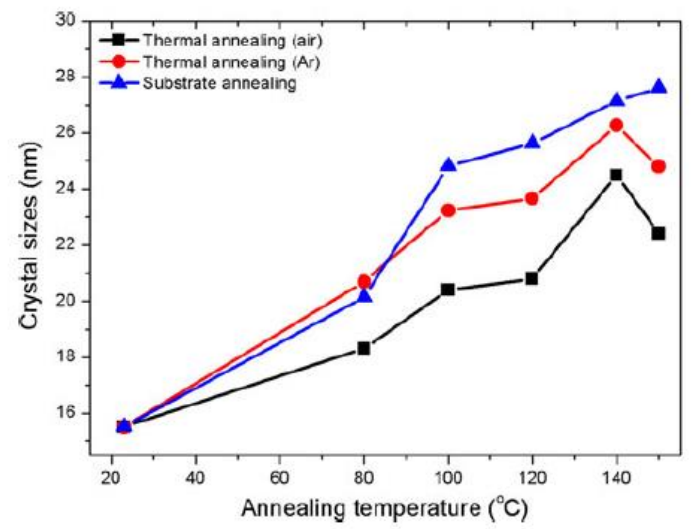

Fig. 2 Evolution of the crystallite sizes as a function of annealing temperature

Hence, the PCBM particles are aggregated easily inside the soft $\mathrm{P}_{3} \mathrm{HT}$, thus resulting in a large extent of phase-separation [32]. It is further observed that at $150^{\circ} \mathrm{C}$, the growth and quantity of the PCBM crystals improves (Fig. 3e). Swinnen et al. [33] noted that the spatial distribution and dimensions of PCBM crystals can be tuned by controlling the P3HT:PCBM blend ratios and annealing conditions. Bull et al. [34] observed the formation of mesoscopic PCBM crystallites in the solvent annealed bulk heterojunction layers and concluded that the formation of large PCBM crystallites does not improve the device efficiency. They postulated that higher device performance can be obtained by inhibiting the formation of larger PCBM crystallites.

To further investigate the effect of temperature, the substrate annealing strategy was carried out at different temperatures. As depicted in the height and phase images, Fig. 4a, $\mathrm{b}$, the substrate annealed film at $80{ }^{\circ} \mathrm{C}$ reveals a possible growth of the "fibrillar-like" structures across the film surface which is related to $\mathrm{P}_{3} \mathrm{HT}$ polymer [35]. 

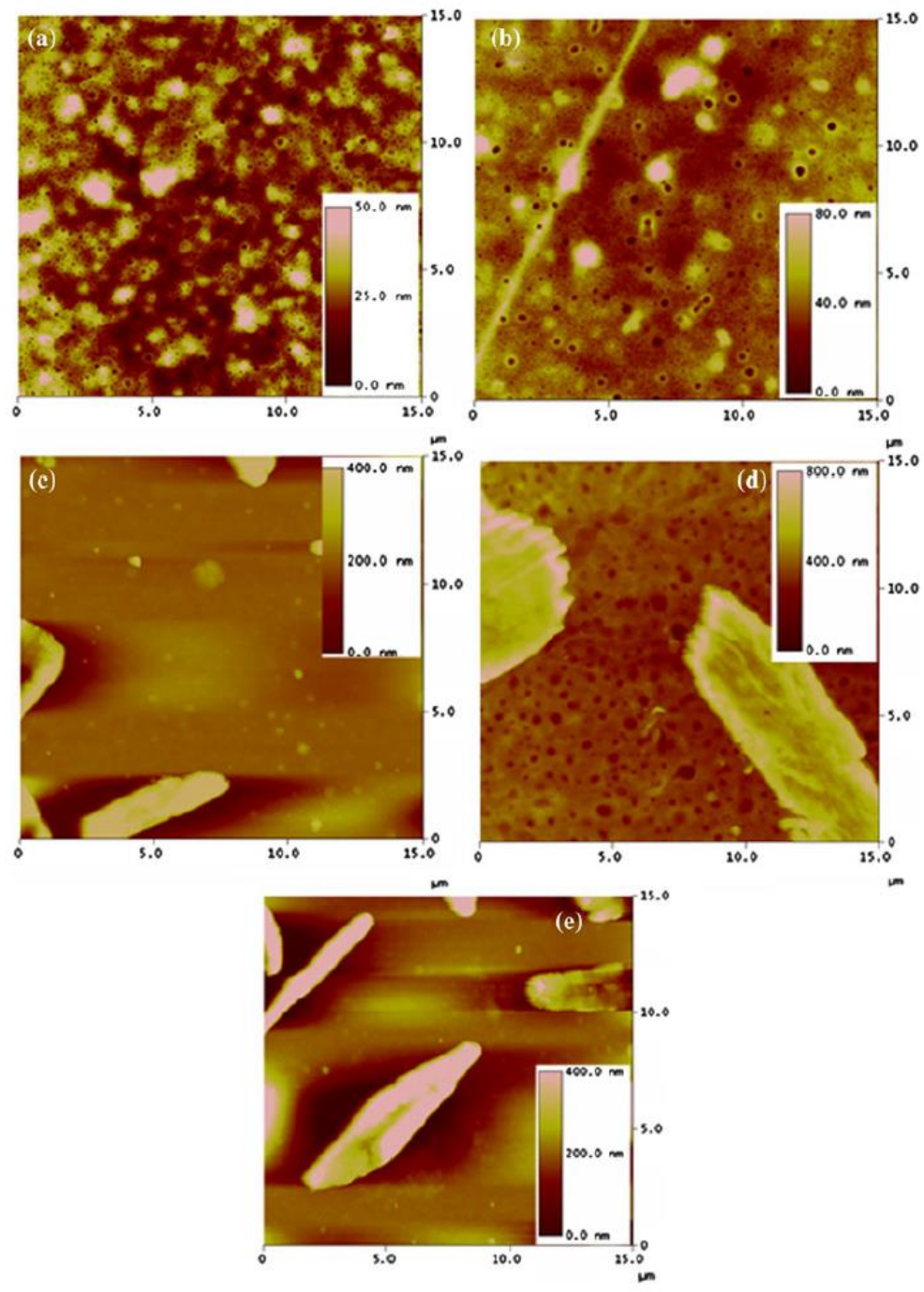

It is interesting to note that after annealing the substrate at $100{ }^{\circ} \mathrm{C}$, the growth and size of the "fibrillar-like" structures increase. Moreover, at $120^{\circ} \mathrm{C}$, as shown in Fig. 4e, f, larger and longer fibrillar structures are predominantly observed across the film. We suggested previously that these fibrillar structures are induced by a large free volume in the blended films after substrate annealing, and that they form due to early crystallization from the presided crystals on a hot substrate, before spin-coating the solution, due to the controlled evaporation rate [36]. Therefore, in this study we validate that the formation of the fibrillar structures is induced by a hot substrate, meaning that a simple drop-casting method can result in the formation of fibrillar structures as shown in the supplementary information, Fig. A1. However, the growth of these "fibril-like" structures is slightly limited, due to the improved formation of the PCBM clusters induced by a drop casting method, on a hot substrate allowing the PCBM molecules to diffuse easily across the film resulting in larger PCBM clusters [32].

However, it is noteworthy to mention that the spin-coating technique reduces the diameter and rearranges the order of the fibrils and suppresses the growth of the fullerene clusters. The pre-annealed substrate, $140{ }^{\circ} \mathrm{C}$, with the film deposited thereafter, demonstrates 
longer fibrils (and with smaller diameter) that are even more locally ordered and better connected with neighbours as shown in Fig. 4g, h. Furthermore, the increased length of the nanorods should reduce the number of required inter-rod hops to traverse the film. This denotes that, annealing at $140{ }^{\circ} \mathrm{C}$ (or $150{ }^{\circ} \mathrm{C}$, results not shown) results in further suppressed diffusion of the PCBM molecules into the blend under the substrate annealing condition, and subsequently restricts any growth of the PCBM crystals/clusters, and thus results in the formation of fibrils that are clearly resolved in both the topography and phase signals across the entire area of the scan.

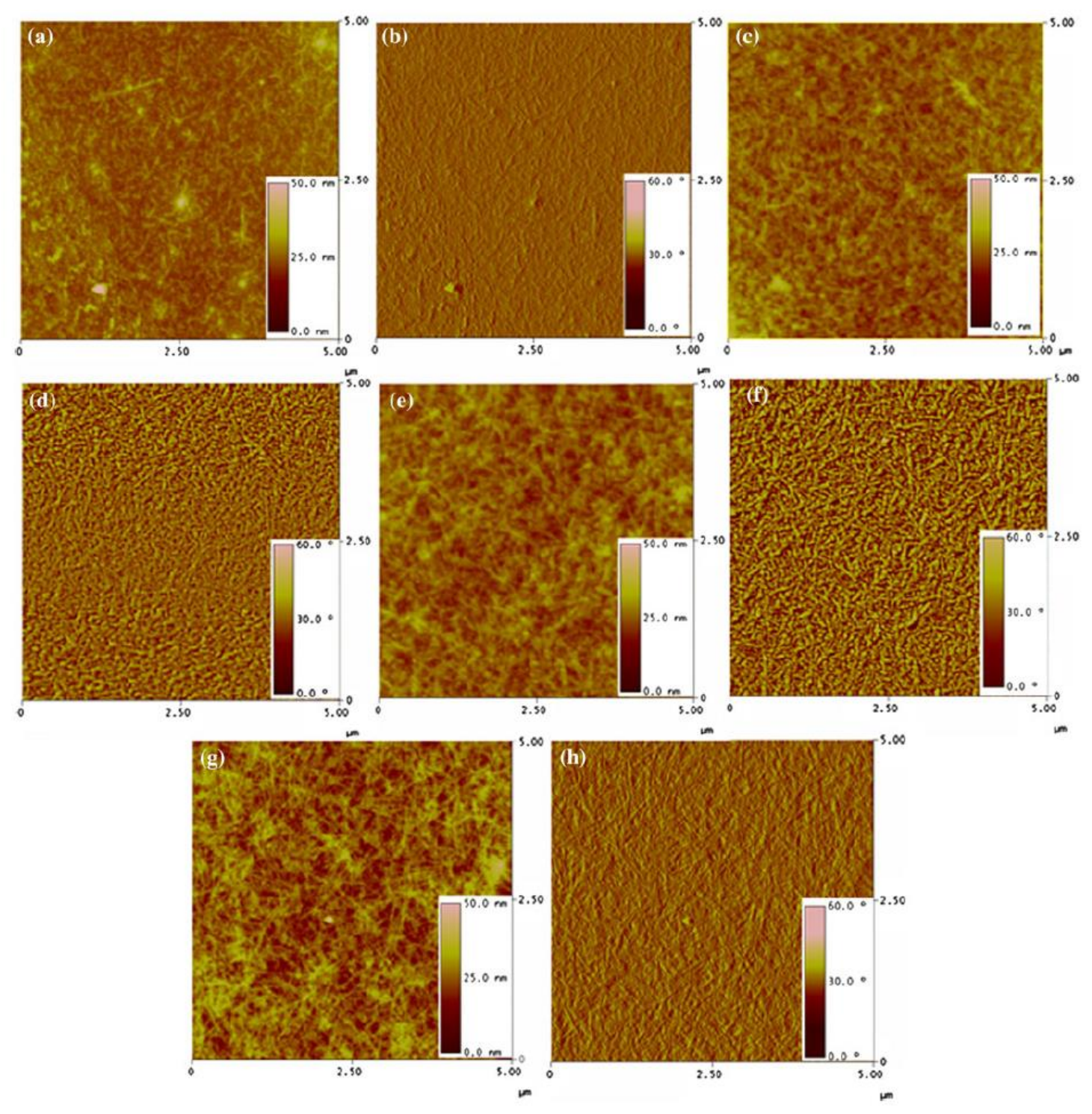

Fig. 4 AFM height and phase images of the substrate annealed P3HT:PCBM films at different temperatures a, b as-prepared, c, d $100{ }^{\circ} \mathrm{C}$, e, f $120^{\circ} \mathrm{C}$, and $140^{\circ} \mathrm{C}(\mathrm{g}, \mathbf{h})$. Note all the substrates were annealed in air for $15 \mathrm{~min}$

To quantitatively investigate the changes in the morphology, the surface roughness (rms) values for the thermally (air and Ar atmospheres) and substrate annealed films were measured as shown in Fig. 5. As depicted in Fig. 5a, b, it is evident that the rms roughness and the PCBM average diameter of the thermally annealed films (air and Ar) increases linearly due to larger PCBM needles, resulting in a macroscopic-phase separation 
between the polymer and PCBM. It should be noted that the average diameter of the PCBM "needle-like" crystals was estimated using SEM and AFM analysis. For substrate annealed films in Fig. 5a, a moderate increase for rms roughness is observed. Such a restrained increase in rms roughness is probably due to the controlled evaporation of the solvent, resulting in the suppressed diffusion of PCBM molecules. Campoy-Quiles et al. [37] suggested that crystallization of the $\mathrm{P}_{3} \mathrm{HT}$ chains occurs first, followed by the diffusion of PCBM molecules to nucleation sites where the PCBM agglomerations grow. From our observations we can conclude that annealing the substrate is an unconventional method whereby highly ordered and crystalline $\mathrm{P}_{3} \mathrm{HT}$ can be obtained. This indicates that highly ordered $\mathrm{P}_{3} \mathrm{HT}$ crystals suppresses or retards the diffusion of PCBM molecules into the blend and subsequently limits the enlarge growth of the PCBM crystals. Therefore, this method provides an alternative approach to produce improved efficiencies.

\section{Polarized optical microscopy}

Polarized optical microscopy (POM) was used to monitor the surface morphology of the blended films spin-coated from CB. Figure 6 shows the microscopic images of the $\mathrm{P}_{3} \mathrm{HT}$ :PCBM films annealed at different temperatures and times. The annealed film at 120 ${ }^{\circ} \mathrm{C}$ (Fig. 6b) reveals a change in its optical clarity, and "needle-like" shaped crystals with different densities grow out to form a 2D network of PCBM needles. When the film is annealed at $140{ }^{\circ} \mathrm{C}$, for $5 \mathrm{~min}$, the number of "needle-like" crystals increases (Fig. 6c). The observed coloured halos around the needles are attributed to the light interference originating from the changes in the film thickness, and is due to the PCBM-depleted regions $[38,39]$. Despite the difference in the density of crystals formed, the individual crystals are of similar shape. The resilient disparity in the crystal density offers insight into the nucleation of the crystals, signifying that the PCBM crystals nucleate at the film surfaces/interfaces. The crystal density contrasts indicate that the two surface/interfaces of the film are not equivalent in terms of crystal nucleation. It was demonstrated by CampoyQuiles et al. [37] that the PCBM tends to be more concentrated at the glass/film interface than at the film/air surface. Thus, the nucleation of the PCBM crystals is correlated with the PCBM concentration at the film surface/interface. Now, the growth of the crystals requires unobstructed space, sufficient energy and temperature to expand. Bjö rströ $\mathrm{m}$ et al. [40] and Wang et al. [41] reported that the PCBM and P3HT have surface energies of 38.2 and $26.9 \mathrm{mN} / \mathrm{m}$, respectively. As a result, the PCBM concentration is reduced at the film/air surface due to its higher surface energy, and therefore the PCBM concentration and density of the crystal nucleation sites is low. However, the film/air surface as well as the higher annealing temperature easily yields space for crystal growth due to improved volume expansion, induced by the soft chains of the polymer and so these nucleation sites always lead to observed crystals [32]. At annealing times of $15 \mathrm{~min}$, the shape of the crystals change and their ends become sharper, as shown in Fig. 6d. It is evident from Fig. 6e that "needle-like" crystals agglomerate at longer annealing times (30 $\mathrm{min}$ ) at the micrometer scale resulting in a degradation of the morphology due to the overgrowth of the PCBM clusters. 

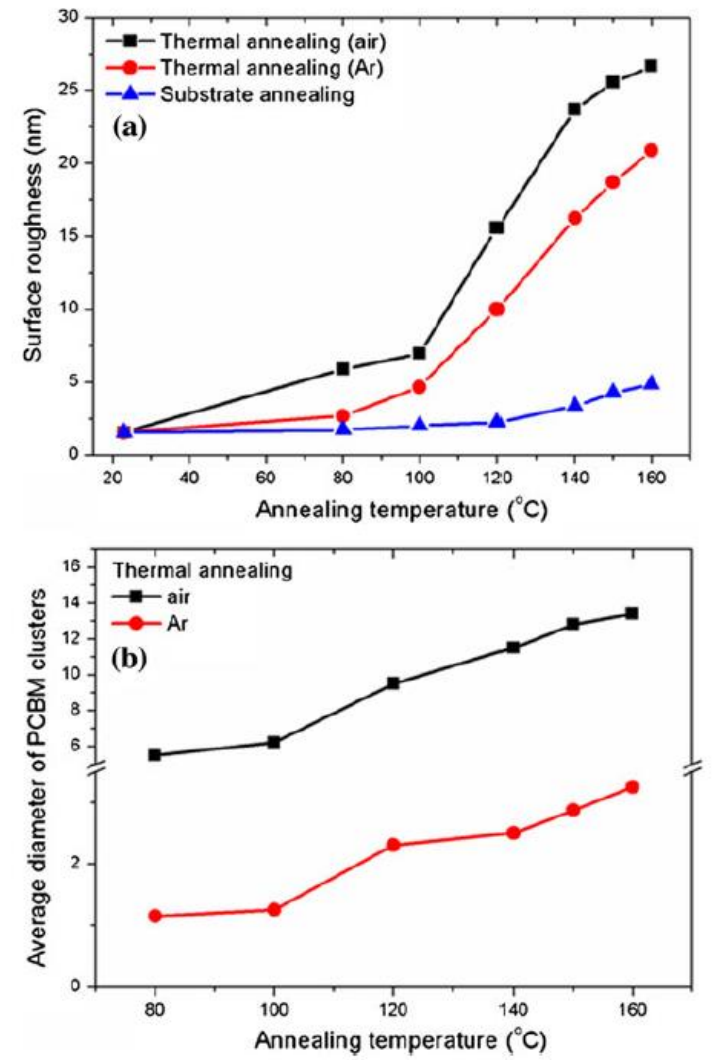

Fig. 5 Evolution of the a surface roughness and $\mathbf{b}$ average diameter of the PCBM crystals as a function of annealing temperature

Optical microscopy micrographs of the annealed films in $\mathrm{Ar}$ atmospheres, Fig. 7, demonstrate small "needle-like" crystals across the film. Fewer amounts of these needles are observed for the film annealed at $80{ }^{\circ} \mathrm{C}$. However, upon increasing the annealing temperature to 120 and $140{ }^{\circ} \mathrm{C}$, the amount of these needles increases, indicating that their growth depend on the temperature. Moreover, the halo surrounding the PCBM clusters is still noticeable on these films. It is worthy to note that an enormous growth of these needles is slightly suppressed (see Fig. 8b, supplementary information Fig. A2) as compared to the films annealed in air, probably due to the flow of the Ar gas that minimises the diffusion of the PCBM molecules. However, up on annealing at $150{ }^{\circ} \mathrm{C}$ or $\left(160{ }^{\circ} \mathrm{C}\right)$, number of the needles increases (see supplementary information Fig. A3) [32]. 

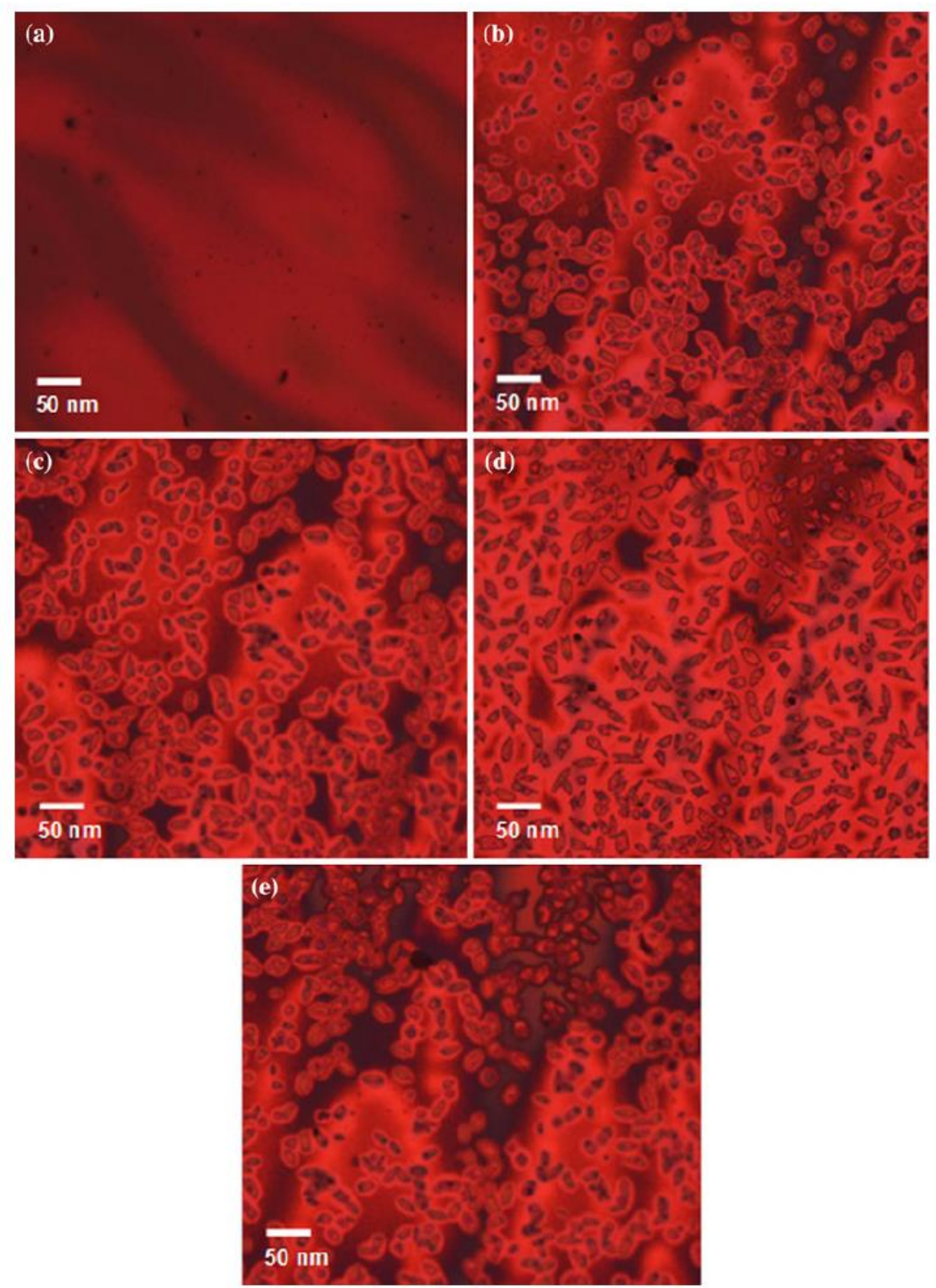

Fig. 6 Phase contrast optical microscopy images of the P3HT:PCBM films annealed in air at a as-prepared (RT), b 120 and $\mathbf{c}-\mathrm{e} 140{ }^{\circ} \mathrm{C}$ (for 5 , 15 and $30 \mathrm{~min})$

\section{Scanning electron microscopy}

To supplement the POM results, HR-SEM analysis was carried out to monitor the surface morphology changes of the P3HT:PCBM blend as shown in Fig. 8. SEM micrographs (Fig. 8a) of the thermally annealed films in air at $140{ }^{\circ} \mathrm{C}(15 \mathrm{~min})$ reveal "needle-like" crystals with different densities. It is evident from the inset that these "needle-like" crystals are in the diameter regime of 10-15 $\mathrm{lm}$ and length of several micrometers, some up to $30 \mathrm{~lm}$. Moreover, an increase in annealing temperature showed that "needle-like" the diameter and length crystal increases (see supplementary info A3). Films annealed in $\mathrm{Ar}$ at $140{ }^{\circ} \mathrm{C}$, demonstrate thinner "needle-like" crystals with diameter regime of about $2 \mathrm{~lm}$ and length 
of $10 \mathrm{~lm}$, as shown in the inset of Fig. 8b. The substrate annealed P3HT:PCBM film at $140{ }^{\circ} \mathrm{C}$ (Fig. 8c), demonstrates fibrillar structures across the film which are up to $500 \mathrm{~nm}$ in length. It can be seen from Fig. 8c, that the fibrillar structures are randomly distributed across the film indicating improved connectivity.

\section{Ultraviolet-Visible spectroscopy}

Photon harvesting is the main key issue to obtain high performance in polymer solar cells. Figure 9 depicts the UV-Vis absorption spectra of the P3HT:PCBM blend annealed at different temperatures and times, as well as through the substrate annealing method. It is observed from Fig. 9a that the annealed films in air show a trivial red-shift and an increase in intensity of the absorption spectra. It is further visible from Fig. 9b that the thermally annealed films in air at different times demonstrate that annealing at shorter times results in improved absorption. Longer annealing time $(30 \mathrm{~min}$ ) reveal a decrease in absorption and a blue-shift in the absorption spectra as compared to the films annealed at shorter times. This indicates that the crystallization process starts rapidly at the first stages of the thermal annealing process.
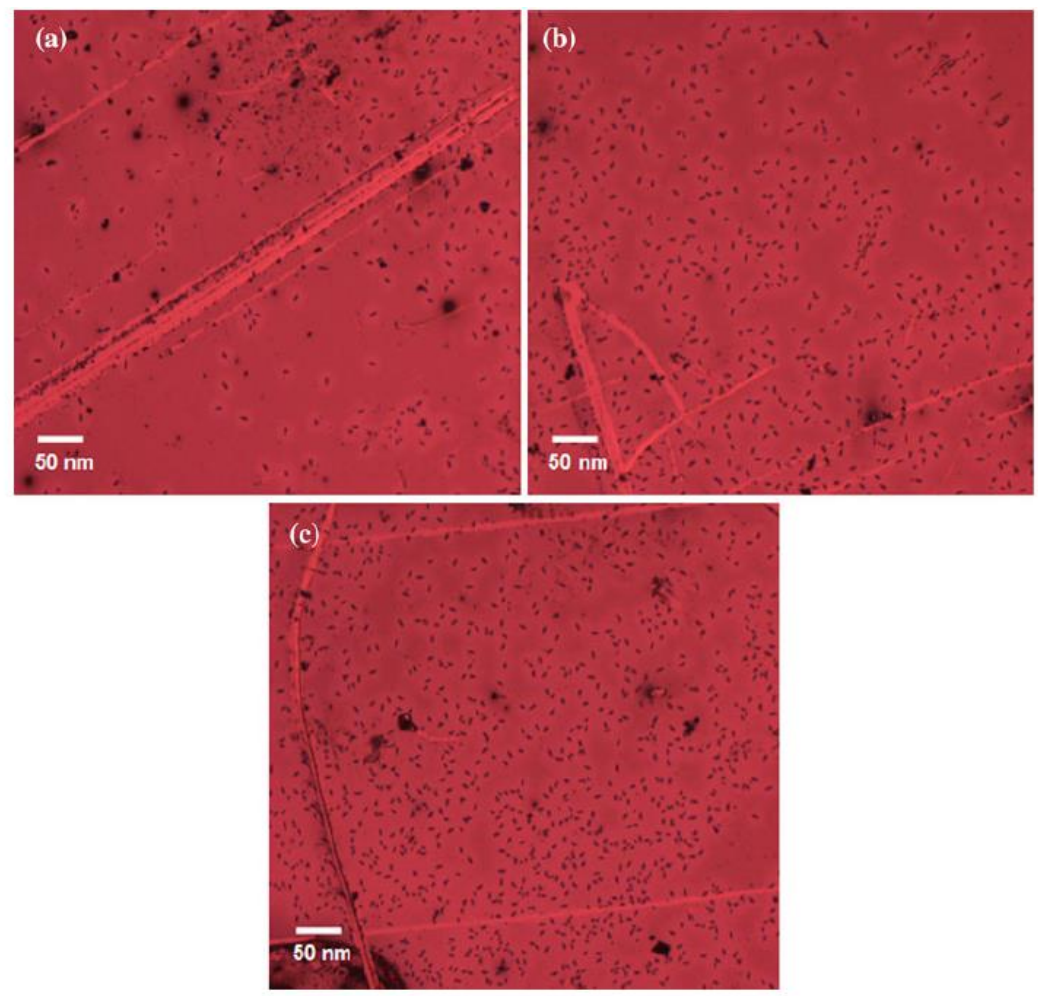

Fig. 7 Phase contrast optical microscopy images of the P3HT:PCBM annealed in Ar atmosphere at a 80, b 120, and c $140{ }^{\circ} \mathrm{C}$. Note scratches on the films are due to sample transportation 


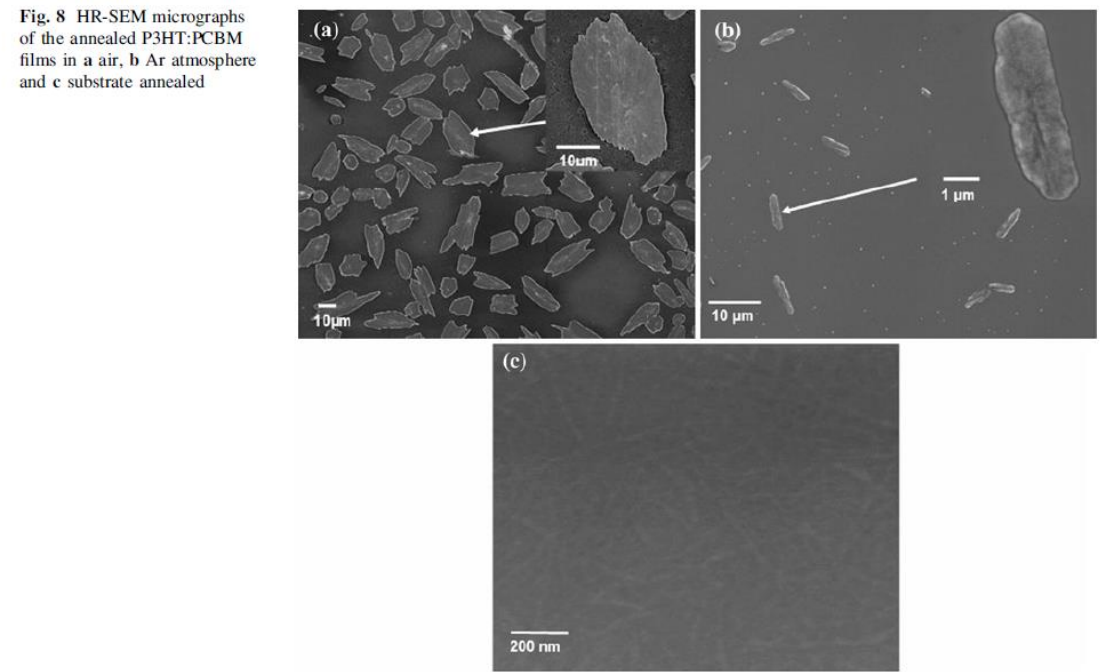

However, substrate annealed films in Fig. 9c reveal a higher degree of $\mathrm{P}_{3} \mathrm{HT}$ absorption which favours more photon harvesting and better device performance. This is evident from a relatively large red-shift of the spectrum in the energy range of $\mathrm{P}_{3} \mathrm{HT}$ absorption, and a reduction in the optical band-gap (Fig. 10) because of an escalation of effective conjugations. Stronger vibronic shoulders at the shorter-energy side of an absorption maximum due to the enhanced interchain interaction [42] also contribute to this.

\section{Spectroscopic ellipsometry}

The refractive index and extinction coefficient, $\mathrm{n}$ and $\mathrm{k}$, of the polymer blend, were obtained by calculating the pseudodielectric functions of $\mathrm{P}_{3} \mathrm{HT}: \mathrm{PCBM}$ films at various angles of incidence (AOI), together with data of $\Psi$ and $\Delta$ (see supplementary info, Fig. A4). The fits displayed excellent agreement between the model calculation and the experimental data, as confirmed by low MSE values listed in Table 1. Figure 11 shows the calculated extinction coefficient (k) of the P3HT:PCBM blend films of the as-prepared and annealed films at various conditions. It is clear from Fig. 11a, that the as-prepared $\mathrm{P}_{3} \mathrm{HT}$ :PCBM film reveals five optical absorptions at the wavelengths of $343,384,515,553$ and $600 \mathrm{~nm}$, respectively. The first two electronic transitions at shorter wavelengths originate from the PCBM $[26,43]$. The optical absorption at 515 and $553 \mathrm{~nm}$ is considered to arise from the $0-0$ transition and the $0-1$ transition of an intrachain exciton $[26,44]$, whereas the transition around $600 \mathrm{~nm}$ is attributed to the singlet excitonic transition of the P3HT conjugated polymer [45]. The singlet exciton is an electron-hole pair with spin o, bound by Coulomb attraction. It is observed from Fig. 11a that the thermally annealed films in air reveal a red-shift of the extinction coefficient and an improved absorption. Upon increasing the annealing temperature to $150{ }^{\circ} \mathrm{C}$, extinction coefficient decreases slightly. However, the annealed films in Ar atmosphere (Fig. 11b) show improved absorption and pronounced shoulders at $605 \mathrm{~nm}$ as compared to films annealed in air. Karagiannidis et al. [46] demonstrated that the extinction coefficient of the $\mathrm{P}_{3} \mathrm{HT}: \mathrm{PCBM}$ film increases with annealing time. It is of interest to note that the optical absorption spectrum related to PCBM is minimised for the substrate annealed films (Fig. 11c). These results are consistent with the AFM analysis, where no (or less) PCBM clusters were observed. It is 
further observed that the extinction coefficient in Fig. 11c is more enhanced as compared to thermally annealed films. The extinction coefficient (at $550 \mathrm{~nm}$ ) for thermally annealed (air and Ar) and substrate annealed films at $150^{\circ} \mathrm{C}$ is centred at $0.137,0.151$ and 0.167 , respectively. This excitonic enhancement is related to the increase of the $\mathrm{P}_{3} \mathrm{HT}$ crystallization, which increases the inter-chain interaction [37, 47]. This is attributed to the controlled growth or restricted diffusion of the PCBM molecules induced by substrate annealing [36].
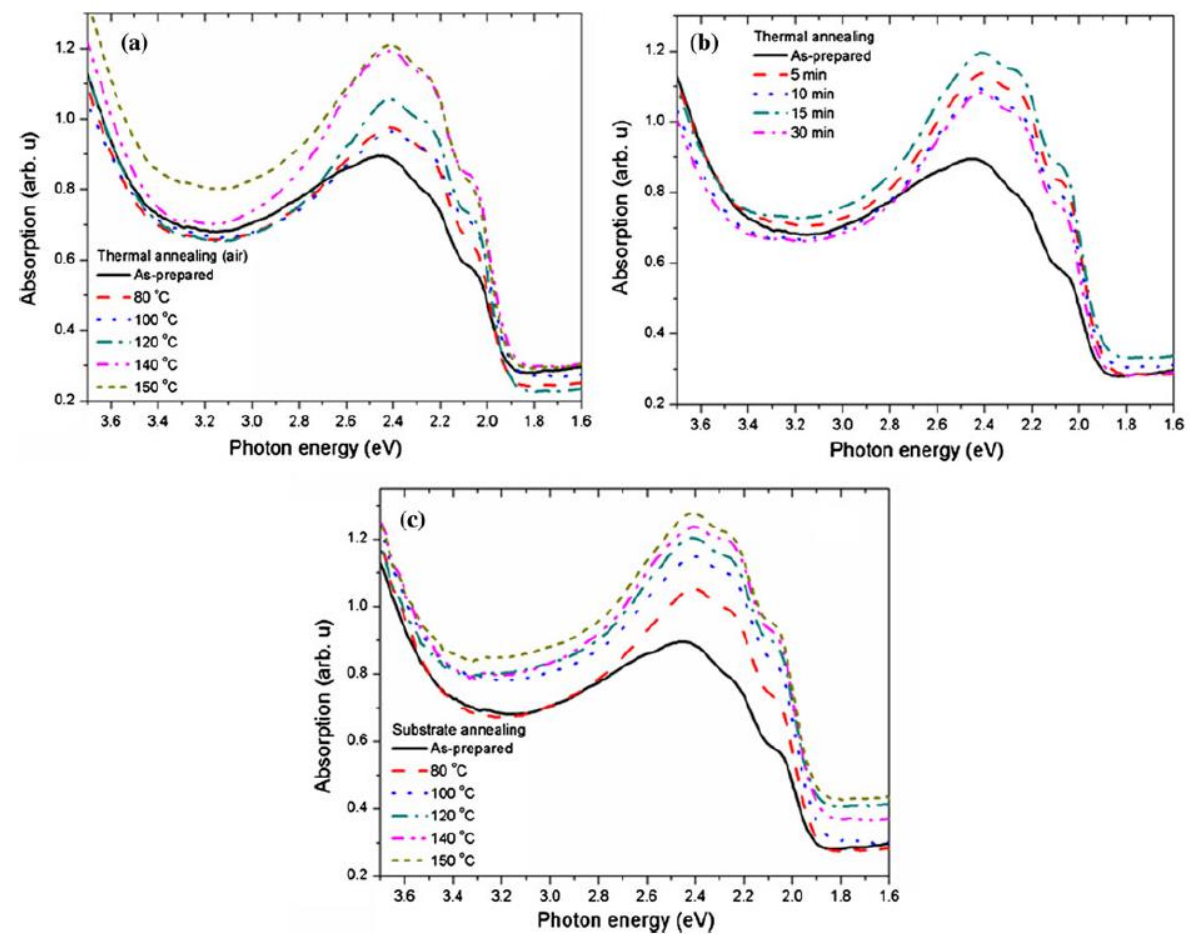

Fig. 9 UV-Vis absorption spectra of the P3HT:PCBM films a annealed in air at different temperatures, $\mathbf{b}$ substrate annealed and $\mathbf{c}$ annealed in air at various times (constant temperature, $140{ }^{\circ} \mathrm{C}$ )

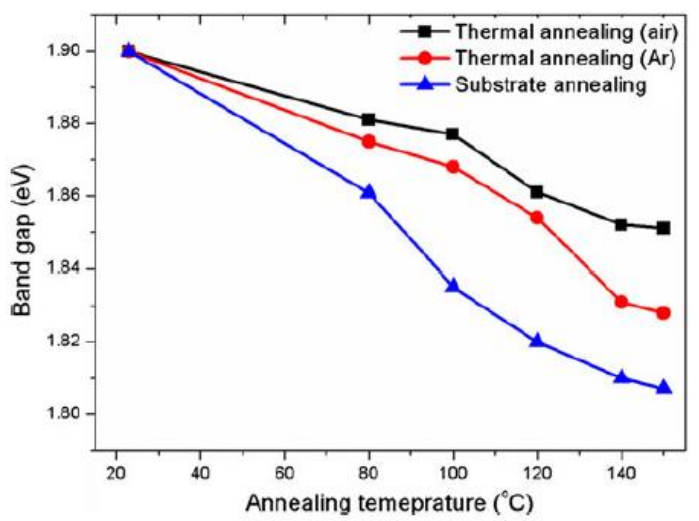

Fig. 10 Evolution of the calculated energy band-gap of the P3HT:PCBM blend as a function of temperature at different annealing conditions

Figure 12 demonstrates the refractive index curves of the $\mathrm{P}_{3} \mathrm{HT}: \mathrm{PCBM}$ films. The peaks of the refractive index are red-shifted due to the enhanced intermolecular order from flatter molecular conformation and reduced torsion of the $\mathrm{P} 3 \mathrm{HT}$ after annealing. The results

\section{http://repository.uwc.ac.za}


demonstrate that the refractive indexes of the films annealed in Ar (Fig. 12b) are slightly improved as compared to the films annealed in air (Fig. 12a). This is due to the reduction in the diffusion of the PCBM molecules, caused by the Ar flow, which prevents the formation of larger PCBM clusters. Moreover, the substrate annealed films shown in Fig. $12 \mathrm{c}$ reveal larger refractive index as compared to films annealed in air and Ar, respectively. The increased refractive index of the substrate annealed samples is due to the increased density of the $\mathrm{P}_{3} \mathrm{HT}$ crystallization, induced by the controlled evaporation rate of the CB solvent.
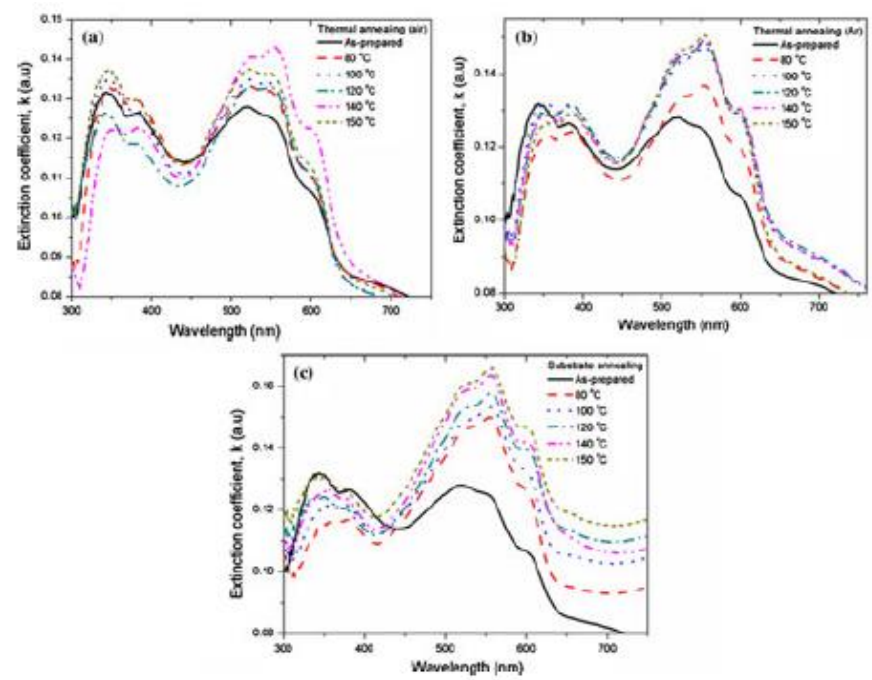

Fig. 11 Calculated a extinction coefficient $(k)$ as a function of wavelength for the P3HT:PCBM films annealed at different conditions: a air, b Ar atmosphere and $\mathbf{c}$ substrate annealing

\section{Photoluminescence spectroscopy}

Photoluminescence measurements of the films annealed at various conditions provide further evidence of the formation of polymer crystallites, as shown in Fig. 13. It is observed that the degree of PL quenching decreases for the annealed films [48] (air and Ar atmospheres), as depicted in Fig. 13a, b. Since PCBM is known to quench the PL of P3HT effectively, therefore, the increase in PL intensity suggests that the interface area between the polymer and PCBM is decreasing. This is due to the fact that the PCBM molecules are diffused away from the $\mathrm{P}_{3} \mathrm{HT}$ polymer chains during annealing, so that the interaction between the $\mathrm{P}_{3} \mathrm{HT}$ polymer chains and PCBM molecules is reduced, leading to a recovery of the PL emission of $\mathrm{P}_{3} \mathrm{HT}$ [49-51]. 

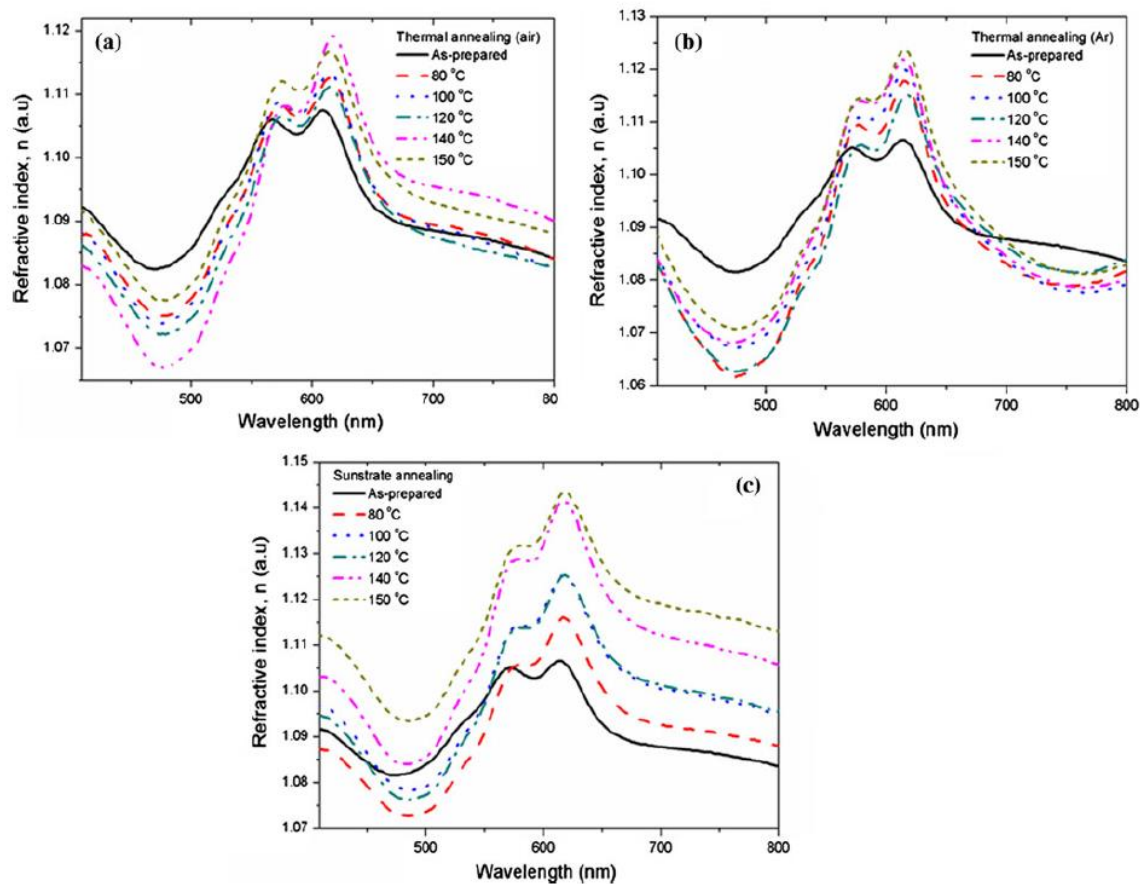

Fig. 12 Calculated refractive index $(n)$ as a function of wavelength for the P3HT:PCBM films annealed at various conditions: a air, b Ar atmosphere and $\mathbf{c}$ substrate annealing
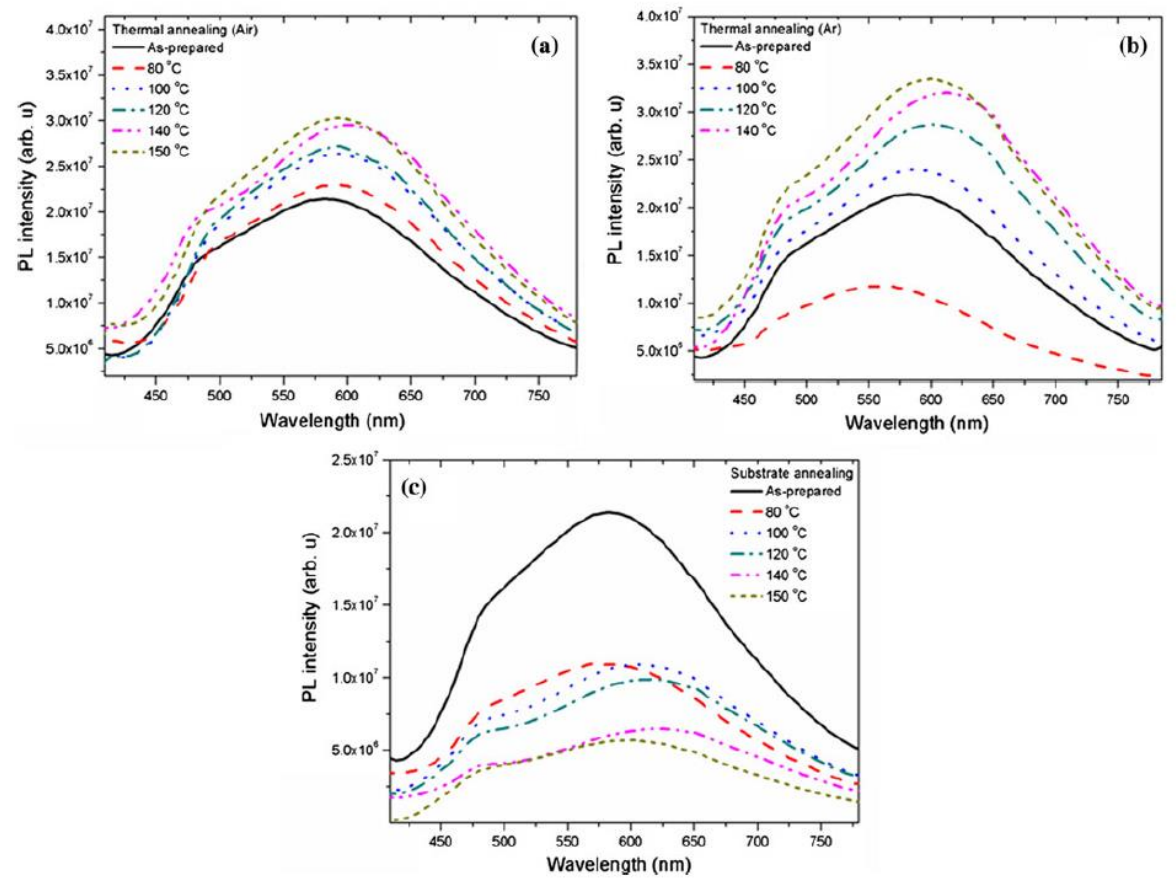

Fig. 13 PL spectra of the annealed P3HT:PCBM films at different conditions: a air, b Ar atmosphere and $\mathbf{c}$ substrate annealing

The more significant increase in the PL intensity of the $\mathrm{P}_{3} \mathrm{HT}: \mathrm{PCBM}$ blend after annealing indicate a higher degree of phase separation between the $\mathrm{P}_{3} \mathrm{HT}$ polymer chains and PCBM molecules. This can be well explained by SEM analysis, as shown in Fig. 8a, b. Larger PCBM needles are observed across the film offering an inappropriate morphology for charge transport. Therefore, most of the photogenerated holes simply 
recombine with electrons which transport through the polymer-rich matrix phase leading to a higher emission.

It is evident from Fig. 13c that the substrate annealed films show reduced PL intensity, indicating a charge transfer between the polymer and PCBM [51]. This charge transfer is more significant for the substrate annealed film at 140 and $150{ }^{\circ} \mathrm{C}$. A quenching of the PL intensity provides direct evidence for exciton dissociation, and thus an efficient PL quenching is necessary to obtain efficient organic solar cells [52]. PL quenching suggests an increase in the interfacial area between the polymer and PCBM materials in the active layer. Moreover, a significant red-shift from 585 to 610,620 and $625 \mathrm{~nm}$ for the as-prepared and the substrate annealed films at 100,120 and $140{ }^{\circ} \mathrm{C}$, as well as $150{ }^{\circ} \mathrm{C}$ showing distinguishable vibronic features is observed. This red-shift in the PL spectra is attributed to the reorganization of the polymer chains and PCBM particles during annealing resulting in a homogeneous phase segregated interpenetrating structure of the donor and acceptor molecules. This facilitates exciton dissociation within the $\mathrm{P}_{3} \mathrm{HT}$ :PCBM heterojunction, stimulating additional quenching of the PL emission from the $\mathrm{P}_{3} \mathrm{HT}$ chains.

\section{Photovoltaic properties}

In order to compare the device performance for different annealing conditions, the $\mathrm{P}_{3} \mathrm{HT}$ :PCBM devices were fabricated. The photovoltaic properties were studied by $J-V$ characteristics under AM $1.5 \mathrm{G}$ condition with illumination intensity of $100 \mathrm{~mW} / \mathrm{cm}^{2}$ and the obtained results are presented in Fig. 14 and Table 2. It can be seen from Fig. 14a that the short-circuit current density $\left(J_{\mathrm{Sc}}\right)$ factor $(\mathrm{FF})$ increase upon annealing the device at $100^{\circ} \mathrm{C}$ in air.
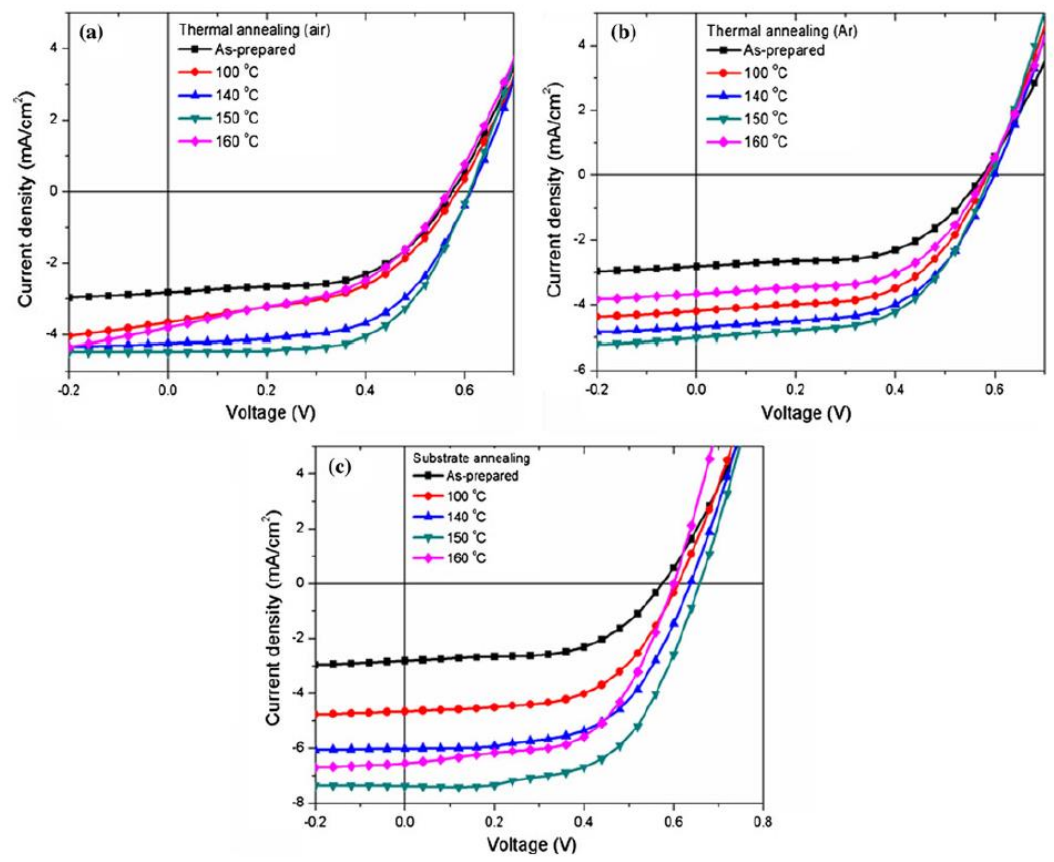

Fig. 14 Current-voltage $(J-V)$ curves of the P3HT:PCBM devices annealed at different conditions: $\mathbf{a}$ in air $\mathbf{b}$ under $\mathrm{Ar}$ atmosphere an c substrate annealing 
With a further increase in annealing temperature, 140 and $150{ }^{\circ} \mathrm{C}$, the $J_{\mathrm{Sc}}$, and $\mathrm{FF}$ improve, resulting to a PCE of about 1.42 and $1.65 \%$, respectively. The restricted PCE for the films annealed in air is probably due to larger PCBM needles offering an inappropriate morphology for charge transport. Parlak [53] demonstrated that higher quantities of PCBM needles lead to less efficient charge transport and lower short current of the polymer solar cells. It is interesting to note that the annealed device under $\mathrm{Ar}$ atmosphere at $150{ }^{\circ} \mathrm{C}$ (Fig. 14b) shows improved efficiency as compared to the device annealed in air. This is probably due to the improved crystallization induced by Ar flow which prevents the formation of larger PCBM clusters across the film. Moreover, it is worthy to note that the substrate annealed devices (Fig. 14c; Table 2) at $150{ }^{\circ} \mathrm{C}$ revealed more improved PCE of about $2.88 \%$, as compared to the devices annealed in air and $\mathrm{Ar}$ atmospheres. This is due to the improved interfacial area, light absorption and the charge transportation property of the highly ordered $\mathrm{P}_{3} \mathrm{HT}$ crystallites [54] induced by substrate annealing resulting in a well-ordered morphology as depicted in Fig. 4.

Based on the various annealing methods described above, we conclude that the substrate annealing strategy facilitates the charge separation and transport to the electrodes, and enhances the formation of an ordered structure as indicated by vibronic peaks in the absorption spectra (Fig. 9c). Therefore, higher absorption, 3D interpenetrating networks and the increase in the carrier mobility are conceivable [36]. This strategy can provide a feasible solution for controlling the crystallization rate of the fullerene molecules by suppressing the formation of larger fullerene crystals, which will therefore result in the evolution of well-ordered bulk-heterojunction (BHJ) morphology such that improved efficiencies are conceivable.

\begin{tabular}{lllll}
$\begin{array}{l}\text { Table 2 Photovoltaic characteristics } \\
\text { annealed at different conditions }\end{array}$ & & P3HT:PCBM & devices \\
\hline $\begin{array}{l}\text { Annealing temperature } \\
\left({ }^{\circ} \mathrm{C}\right)\end{array}$ & $\begin{array}{l}V_{\mathrm{oc}} \\
(\mathrm{V})\end{array}$ & $\begin{array}{l}J_{\mathrm{sc}}(\mathrm{mA} / \\
\left.\mathrm{cm}^{2}\right)\end{array}$ & FF & $\begin{array}{l}\text { PCE } \\
(\%)\end{array}$ \\
\hline Annealed in air & & & & \\
As-prepared (RT) & 0.57 & 2.81 & 0.49 & 0.79 \\
100 & 0.58 & 3.64 & 0.53 & 1.12 \\
140 & 0.61 & 3.89 & 0.55 & 1.42 \\
150 & 0.60 & 4.43 & 0.61 & 1.65 \\
160 & 0.57 & 3.81 & 0.46 & 0.99 \\
Annealed in Ar & & & & \\
As-prepared (RT) & 0.57 & 2.81 & 0.49 & 0.79 \\
100 & 0.59 & 4.19 & 0.56 & 1.40 \\
140 & 0.60 & 4.70 & 0.56 & 1.60 \\
150 & 0.60 & 5.02 & 0.58 & 1.74 \\
160 & 0.58 & 3.65 & 0.57 & 1.21 \\
Substrate annealed & & & & \\
As-prepared (RT) & 0.57 & 2.81 & 0.49 & 0.79 \\
100 & 0.61 & 4.73 & 0.56 & 1.62 \\
140 & 0.64 & 6.01 & 0.57 & 2.19 \\
150 & 0.65 & 7.37 & 0.60 & 2.88 \\
160 & 0.60 & 6.55 & 0.57 & 2.24 \\
\hline & & & & \\
\hline
\end{tabular}




\section{Conclusion}

In summary, a possible method for evaluating optimal annealing temperature and annealing time of $\mathrm{P}_{3} \mathrm{HT}: \mathrm{PCBM}$ through conventional and substrate annealing prior to deposition of the active layer was developed. The substrate annealing strategy resulted in a more favourable morphology than the thermal annealing in air and $\mathrm{Ar}$ atmospheres. Conventional annealing and prolonged heat treatment resulted in extensive phase separation and incomplete charge transfer, as demonstrated by the growth in the size and quantity of PCBM "needle-like" crystals, resulting in a degradation of the morphology. This was attributed to the relatively fast diffusion and aggregation of the PCBM molecules during $\mathrm{P}_{3} \mathrm{HT}$ crystallization. The substrate annealing of the blended films demonstrated formation of a well-ordered morphology, revealing fibrillar structures. This resulted in improved optical constants, PL quenching and a decrease in the P3HT bad-gap due to the suppressed diffusion and aggregation of the PCBM molecules. These results demonstrate an effective strategy that determines an optimized annealing treatment approach to produce improved efficiencies through substrate annealing. Consequently, a power conversion efficiency of about $2.88 \%$ was attained through this strategy.

\section{Acknowledgements}

The authors acknowledge the financial support of the Department of Science and Technology (DST) and the Council for Scientific and Industrial Research (CSIR) (Project Nos. HGER28P and HGER27S). 


\section{References}

1. Lungenschmied C, Dennler G, Neugebauer H, Sariciftci NS, Glatthaar M, Meyer T, Meyer A (2007) Sol Energy Mater Sol Cells 91:379

2. Tipnis R, Bernkopf J, Jia S, Krieg J, Li S, Storch M, Laird D (2009) Sol Energy Mater Sol Cells 93:442

3. Blankenburg L, Schultheis K, Schache H, Sensfuss S, Schrö dner M (2009) Sol Energy Mater Sol Cells 93:476

4. Krebs FC, Jørgensen M, Norrman K, Hagemann O, Alstrup J, Nielsen TD, Fyenbo J, Larsen K, Kristensen J (2009) Sol Energy Mater Sol Cells 93:422

5. Ma W, Yang C, Gong X, Lee K, Heeger AJ (2005) Adv Funct Mater 151:617

6. Äich BR et al (2012) Org Electron. http://dx.doi.org/10.1016/ j.orgel.2012.05.001

7. Konarka Technologies home page. http://www.konarka.com/ index.php/site/pressreleasedetail/konarkas_power_plastic_achieves_world_record_8 3_efficiency_certification_fr.Accessed 16June 12

8. Mitsubishi Chemical Corporation Homepage. http://www. mitsubishichemhd.co.jp/english/news_release/index.html. Accessed 16 June 2012

9. Krebs FC (2008) Sol Energy Mater Sol Cells 92:715

10. Krebs FC, Nielsen TD, Fyenbo J, Wadstrøm M, Pedersen MS (2010) Energy Environ Sci 3:512

11. Krebs FC, Fyenbo J, Jørgensen M (2010) J Mater Chem 20:8994

12. Hoppe H, Sariciftci NS (2006) J Mater Chem 16:45

13. Padinger F, Rittberger RS, Sariciftci NS (2003) Adv Funct Mater 13:85

14. Ma W, Yang C, Heeger AJ (2007) Adv Mater 19:1387

15. Motaung DE, Malgas GF, Arendse CJ (2011) J Mater Sci 46:4942. doi:10.1007/s10853-011-5408-9

16. Jeon JH, Lee HK, Wang DH, Park JH, Park OO (2012) Sol Energy Mater Sol Cells 102:196

17. Shen Y-M, Chen C-S, Yang P-C, Ma S-Y, Lin C-F (2012) Sol Energy Mater Sol Cells 99:263

18. Peet J, Soci C, Coffin RC, Nguyen TQ, Mikhailovsky A, Moses D, Bazan GC (2006) Appl Phys Lett 89:252105

19. Chen F-C, Tseng H-C, Ko C-J (2008) Appl Phys Lett 92:103316

20.Lee JK, Ma WL, Brabec CJ, Yuen J, Moon JS, Kim JY, Lee K, Bazan GC, Heeger AJ (2008) J Am Chem Soc 130:3619

21. Moulé AJ, Meerholz K (2008) Adv Mater 20:240

22. Motaung DE, Malgas GF, Arendse CJ (2010) Synth Met 160:876

23. Reisdorffer F, Haas O, Le Rendu P, Nguyen TP (2012) Synth Met 161:2544

24. Li G, Shrotriya V, Yao Y, Huang J, Yang Y (2007) J Mater Chem 17:3126

25. Cugola R, Giovanella U, DiGianvincenzo P, Bertini F, Catellani M, Luzzati S (2006) Thin Solid Films 511-512:489

26. Madsen MV, Sylvester-Hvid KO, Dastmalchi B, Hingerl K, Norrman K, Tromholt T, Manceau M, Angmo D, Krebs FC (2011) J Phys Chem C 115:10817

27. Woollam JA (2008) Inc. Complete Ease ${ }^{\mathrm{TM}}$ Data Analysis Manual 28.Jellison GE (1993) Thin Solid Films 234:416 
29. Erb T, Zhokhavets U, Gobsch G, Raleva S, Stühn B, Schilinsky P, Waldauf C, Brabec CJ (2005) Adv Funct Mater 15:1193

30. Chirvase D, Parisi J, Hummelen JC, Dyakonov V (2004) Nano-technology 15:1317

31. Cullity D (1956) Elements of X-ray diffraction. Addison-Wesley, Reading

32. Malgas GF, Motaung DE, Arendse CJ (2012) J Mater Sci 47:4282. doi:10.1007/s10853-012-6278-5

33. Swinnen A, Haeldermans I, vande Ven M, D'Haen J, Vanhoyland G, Aresu S, D’Olieslaeger M, Manca J (2006) Adv Funct Mater 16:760

34. Bull TA, Pingree LSC, Jenekhe SA, Ginger DS, Luscombe CK (2009) ACS Nano $3: 627$

35. Singh RK, Kumara J, Singh R, Kant R, Chand S, Kumar V (2007) Mater Chem Phys 104:390

36. Motaung DE, Malgas GF, Arendse CJ, Malwela T (2010) Mater Chem Phys 124:208

37. Campoy-Quiles M, Ferenczi T, Agostinelli T, Etchegoin PG, Kim Y, Anthopoulos TD, Stavrinou PN, Bradley DDC, Nelson J (2008) Nat Mater 7:158

38. Chang L, Lademann HWA, Bonekamp J-B, Meerholz K, Moulé AJ (2011) Adv Funct Mat 21:1779

39. Erb T, Zhokhavets U, Hoppe H, Gobsch G, Al-Ibrahim M, Ambacher O (2006) Thin Solid Films 511-512:483

40. Bjö rströ m CM, Nilsson S, Bernasik A, Budkowski A, Andersson M, Magnusson KO, Moons E (2007) Appl Surf Sci 253:3906

41. Wang X, Ederth T, Inganas O (2006) Langmuir 22:9287

42. Kim Y, Cook S, Tuladhar SM, Choulis SA, Nelson J, Durrant JR, Bradley DDC, Giles M, McCulloch I, Ha C-S, Lee M (2006) Nat Mater 5:197

43. Harris DC, Bertolucci MD (1978) Symmetry and spectroscopy. Oxford University Press, New York

44. Motaung DE, Malgas GF, Arendse CJ, Mavundla SE (2012) Mater Chem Phys 135:401

45. Lioudakis E, Othonos A, Alexandrou I, Hayashi Y (2007) Appl Phys Lett 91:111117

46. Karagiannidis PG, Georgiou D, Pitsalidis C, Laskarakis A, Logothetidis S (2011) Mater Chem Phys 129:1207

47. Motaung DE, Malgas GF, Arendse CJ (2010) J Mater Sci 45:3276. doi:10.1007/s10853-010-4339-1

48. Bagienski W, Gupta MC (2011) Sol Energy Mater Sol Cells 95:933

49. Motaung DE, Malgas GF, Arendse CJ, Mavundla SE, Knoesen D, Oliphant CJ (2009) Sol Energy Mater Sol Cells 93:1674

50.Zhang F, Zhuo Z, Zhang J, Wang X, Xu X, Wang Z, Xin Y, Wang J, Wang J, Tang W, Xu Z, Wang Y (2012) Sol Energy Mater Sol Cells 97:71

51. Motaung DE, Malgas GF, Arendse CJ, Mavundla SE, Knoesen D (2009) Mater Chem Phys 116:279

52. Wang T-L, Yeh A-C, Yang C-H, Shieh Y-T, Chen W-J, Ho T-H (2011) Sol Energy Mater Sol Cells 95:3295

53. Parlak EA (2012) Sol Energy Mater Sol Cells 100:174 
54. Ho C-S, Huang E-L, Hsu W-C, Lee C-S, Lai Y-N, Yao E-P, Wang C-W (2012) Synth Met 162:1164 